\title{
Pandillas juveniles en Centroamérica o la difícil búsqueda de justicia en una sociedad violenta
}

\author{
Manfred Liebel
}

Desde la década de 1960 surge entre los jóvenes que viven en los barrios populares de las urbes latinoamericanas un nuevo tipo de agrupaciones, conocido en México como chavos banda. Referente a la región centroamericana, donde se habla de maras y pandillas juveniles, el artículo da una visión de la historia y extensión de estos grupos, y analiza sus características sociales, actividades y significados. La investigación dedica especial atención a los modelos culturales y a las nociones sobre los valores y las relaciones sociales en las pandillas. El autor sondea los motivos y las causas que llevan a los jóvenes a organizarse en este tipo de agrupaciones, poniendo especial énfasis en el tema de la violencia e interpretando la actuación de las y los pandilleros como una difícil búsqueda de una sociedad más justa.

As of the 1960s, a new type of grouping emerged among young people living in the poorer neighborhoods of Latin American cities, in Mexico they are known as chavo banda (gangsters). Regarding the Central America region, where they are called Maras and juvenile gangs, this article gives a view on the history and extension of these groups, and analyzes their social characteristics, activities and significance.The research pays special attention to cultural models and the notions on values and social relationships in gangs. The author sounds out the motives and causes which lead young people to organize themselves into this type of group, placing special emphasis on the theme of violence and interpreting the behavior of gangsters as a difficult quest for a fairer society.

MANFRED LIEBel: Universidad Técnica de Berlín. 
"Agárrame la onda, bato."1

$\mathrm{D}$ esde los años sesenta del siglo XX un tipo muy específico de grupos juveniles se extiende como una sombra en los barrios marginales de las grandes ciudades de América Latina. Los jóvenes les dan a sus grupos nombres como Los Sacaojos, Comemuerto o Vatos Locos para diferenciarse aún más de los otros, nombres que - a veces de manera autoirónica- hacen hincapié en sus características y, en general, acentúan lo que es común a cada grupo.

Según el país o la región sus agrupaciones son denominadas como pandillas, bandas, galladas, clicas, parches, maras, chimbas, barras, etc., y sus integrantes se llaman a sí mismos pandilleros(as), chavos(as) bandas, cholos(as), mareros(as), chapulines, etc. Los jóvenes toman estas expresiones en parte de la prensa o de la policía, que las utilizan de manera peyorativa, y les dan una significación propia. En Centroamérica se habla de pandillas, pero se ha generalizado también la expresión maras (sobre todo en El Salvador, Guatemala y Honduras). ${ }^{2}$ Por lo tanto, cuando en este artículo hablo de pandillas o de maras, ambos términos tendrán el mismo sentido.

Las expresiones sugieren que se trata de agrupamientos de jóvenes cuyos asuntos y sentido de la vida están centrados en la violencia, el robo y las drogas. La imagen pública y la visión que se tiene de ellos están muy impregnadas por los medios de comunicación masiva, que de manera casi unánime catalogan a estos grupos como la peor forma de delincuencia y decadencia social, y que con sus diabólicos reportajes estigmatizan a los jóvenes como engendros del infierno a los que hay que tratar con mano dura. ${ }^{3}$

\footnotetext{
${ }^{1}$ Dicho de pandilleros en El Salvador, citado por Escobar (1996: 328).

${ }^{2}$ En Costa Rica se habla en ocasiones de barras y chapulines.

${ }^{3}$ La cantante de rock Lorena Cuerno, quien ha realizado un estudio sobre las maras y está realizando con ellas proyectos musicales, observa: "No sólo mara es, en El Salvador actual, una palabra con una connotación negativa, sino que se ha convertido en un estigma para calificar a todo aquel que parece marero. Así, el que está tatuado o escucha heavy metal, se presume marero y, por implicación, un delincuente común" (Cuerno, 2000: 62). El sociólogo nicaragüense José Luis Rocha (2001: 439) caracteriza a los reportajes sobre las pandillas como pretender
}

El hablar de maras o pandillas puede favorecer este estereotipo, no sólo porque el término tiene un contenido negativo, sino también porque divide de manera rígida a los jóvenes. En vez de tener en cuenta la diversidad de conformaciones de estos grupos, se tiende a reducirlos a los términos opuestos de "bueno" y "malo". Esta visión blanco-negro tiene muy poco que ver con la vida real, las actividades y, sobre todo, con los motivos y la percepción de sí mismos que tienen los jóvenes y con la manera en que se organizan.

Pero, ¿ cómo escapar de este dilema? Las agrupaciones juveniles se diferencian en sus expresiones, formas de organización y en lo que se da por sobreentendido en cada una de ellas, por lo menos del mismo modo y de manera tan fuerte como se diferencian la situación de vida y la historia personal de sus actores. Para las agrupaciones de las que trata este trabajo no hay ninguna denominación que esté libre de connotaciones negativas - y esto no es casualidad - . El intento de denominaciones "neutrales" para salirse del estereotipo, como por ejemplo grupos espontáneos, grupos informales o formas de agrupación juvenil, no conducen a nada porque son muy generales y no toman en cuenta las características de estas agrupaciones.

Para contrarrestar los estereotipos más usuales pondré especial atención a la vida interna de las pandillas y a sus actividades de hecho, sus motivos y sus explicaciones propias. Los jóvenes no deben ser entendidos como recipientes vacíos rellenados por adultos, a los cuales solamente imitan, sino como sujetos que tienen ideas propias así como una estrategia vital particular y que crean sus propias culturas. Con esto quedará claro que el caso de las pandillas se trata de un fenómeno social múltiple que abarca desde los pequeños grupos de "esquineros" hasta las su-

\footnotetext{
"apagar el fuego con gasolina”. A este tipo de reportajes corresponden las medidas actuales de los gobiernos de El Salvador (Plan "Mano Dura"), de Honduras (Plan "Libertad") y de Guatemala (Plan "Escoba"), todas exclusivamente de corte represivo (Equipo..., 2003). En estos países, organizaciones de derechos humanos denunciaron recientemente que el número de jóvenes asesinados por parecer pandilleros aumentó de manera alarmante, sólo en Honduras murieron al menos 1000 jóvenes durante el año 2003. "Equivalen a un genocidio aunque a muchos les molesta este término”, manifestó la presidenta del Comité de Familiares de Detenidos Desaparecidos (COFADEH) en este país (La Prensa, Managua, 30 de diciembre de 2003).
} 


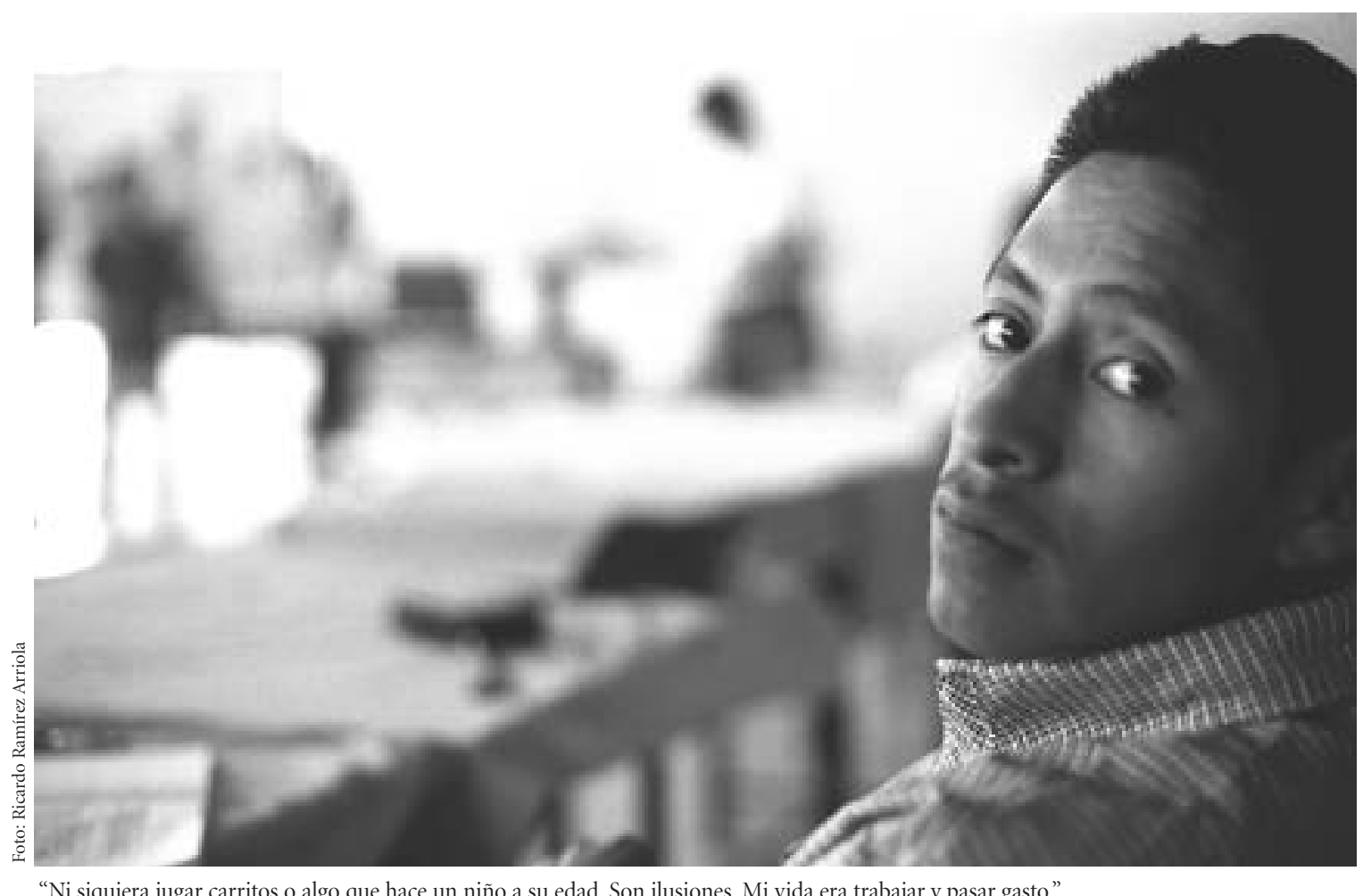

"Ni siquiera jugar carritos o algo que hace un niño a su edad. Son ilusiones. Mi vida era trabajar y pasar gasto."

tilmente estructuradas organizaciones que llegan a adquirir carácter internacional. Además, cada grupo tiene sus peculiaridades. Hay diferencias entre las pandillas de varios países y estas pandillas se van transformando con el paso del tiempo.

En este artículo, después de presentar una sinopsis sobre las investigaciones realizadas, esbozaré la historia de las pandillas juveniles en algunos países centroamericanos para dar una visión de los diferentes tipos de agrupaciones y maneras de conformación. En un segundo paso explicaré las características sociales y los elementos de la situación vital de los pandilleros y las pandilleras. Seguidamente, me dedicaré a las principales actividades de las pandillas y a los significados que los pandilleros dan a estas actividades. Luego dedicaré mayor atención a los modelos culturales, las nociones sobre los valores y las relaciones sociales en las pandillas, y analizaré los significados que tiene el grupo para sus integrantes. Finalmente, intento sondear los motivos y las causas que llevan a los jóvenes a organizarse en pandillas, poniendo especial interés en el tema de la violencia.

\section{INVESTIGACIÓN SOCIAL EN CENTROAMÉRICA}

A diferencia de México (Valenzuela Arce, 1988, 2002; Reguillo Cruz, 1995; Feixa, 1998; Urteaga Castro-Pozo, 2000) y Colombia (Ardila Pedraza et al., 1995; Salazar, 1990, 2002), las pandillas juveniles se convirtieron en Centroamérica en un tema de investigación social sólo a partir de mediados de la década de 1990, aunque en Guatemala se había iniciado, ya en 1987, un estudio de investigación que se ocupó con especial atención de las perspectivas de los jóvenes pandilleros (AVANCSO, 1988).

Un nuevo empuje para la investigación lo dió el Instituto Universitario de Opinión Pública de la Universidad Centroamericana (UCA) en San Salvador, el cual realizó 


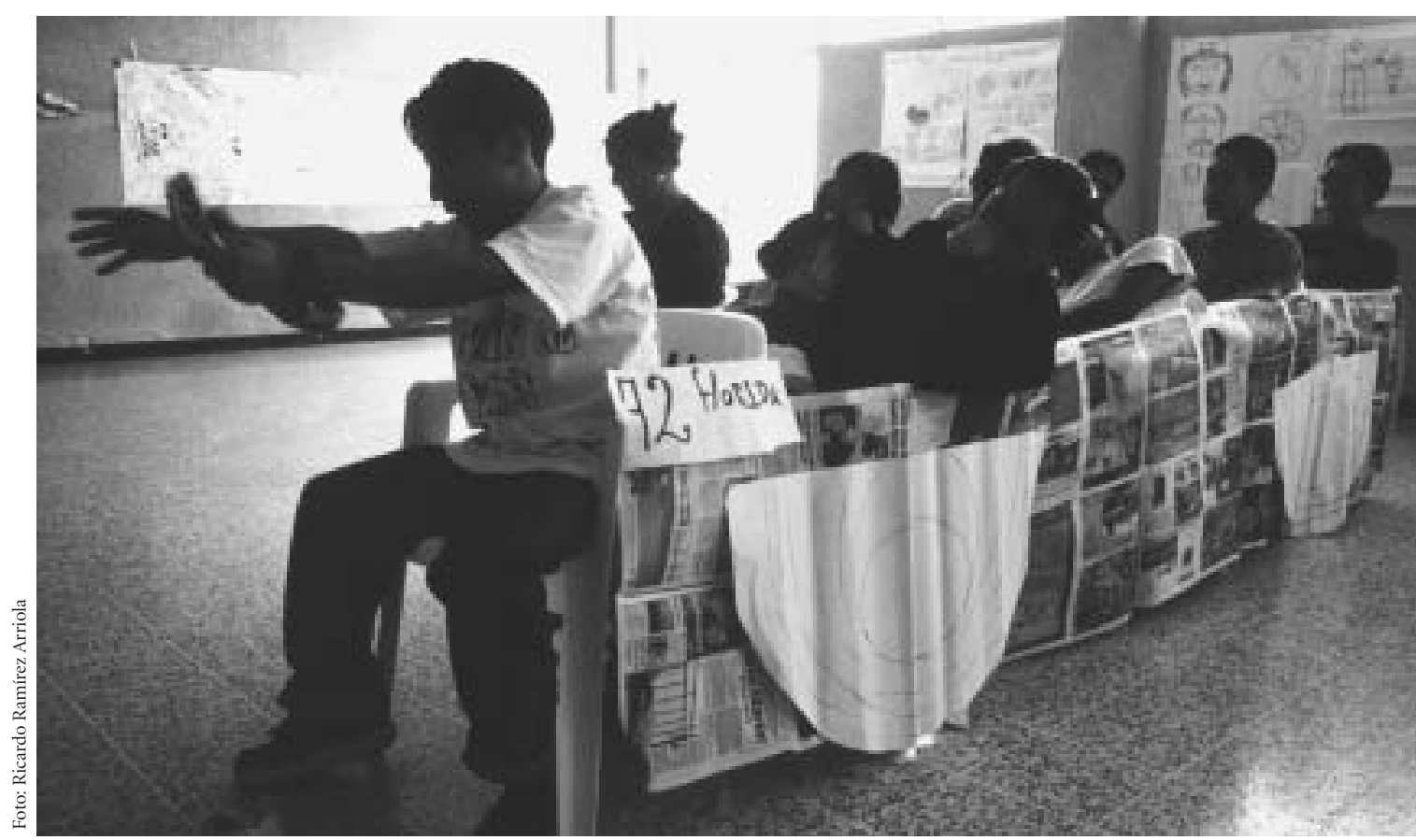

Jóvenes, ex pandilleros, nuevos educadores, comparten vivencias y se capacitan en derechos humanos, participación ciudadana y educación popular.

en 1996 una gran investigación con pandilleros de la capital salvadoreña (IUDOP, 1997; Cruz y Portillo Peña, 1998). La investigación se destaca por el método utilizado, en el que los pandilleros son incluidos como sujetos activos en el proceso de investigación. Los jóvenes no solamente rellenaron las encuestas, sino que incluso participaron en la planificación de la investigación, la redacción de las encuestas y también en la discusión y el análisis de los resultados. Aparte de las encuestas se desarrolló un grupo de discusión con miembros femeninos de las maras. ${ }^{4}$ Cuatro años más tarde, el mismo instituto realizó una investigación comparativa con 938 pandilleros y pandi-

\footnotetext{
${ }^{4}$ El proceso está detalladamente descrito en Cruz y Portillo Peña (1998: 173-183). Tuvo como consecuencia que varios jóvenes de diferentes maras formaran un grupo con el nombre de Homies Unidos, que sin renunciar a su identidad de pandilleros, abogaban por el entendimiento entre las maras y la renuncia a la violencia. El enfoque de la investigación se correspondía en parte con el denominado "intervención sociológica" aplicado en un estudio francés respecto a las pandillas juveniles en las banlieus de Lyon (Dubet, 1987).
}

lleras de la gran región de San Salvador, así como de los municipios de Quezaltepeque, Cojutepeque y Nejapa (Santacruz Giralt y Concha-Eastman, 2001). ${ }^{5}$

En Honduras fue en 1998 que un sociólogo se ocupó por primera vez explícitamente de las pandillas juveniles. El estudio se centra en 86 jóvenes condenados por el juzgado de menores en San Pedro Sula. Por lo demás, se basa exclusivamente en fuentes secundarias (Orellana Maglioni, 1998). ${ }^{6}$ En Nicaragua, un joven antropólogo británico, quien se unió a una pandilla durante diez meses en un barrio de Managua, presentó un informe multifa-

\footnotetext{
${ }^{5}$ La encuesta quedó de nuevo en manos de los jóvenes organizados en Homies Unidos, que ahora se llaman "pandilleros calmados" (para comparar el proceso de investigación véase Santacruz Giralt y Concha-Eastman (2001: 46-58). Además, se pueden mencionar sobre El Salvador los estudios cualitativos de Smutt y Miranda (1998) y Cuerno (2000), así como un estudio psicológico anterior de Argueta et al. (1992).

${ }^{6}$ Además, el tema es referido desde 1993 de manera esporádica en estudios que se ocupan del aspecto de los derechos humanos y de las diferentes formas de violencia en Honduras (Salomón, 1993; y Salomón, Castellanos y Flores, 1999).
} 
cético en 1997 (Rodgers, 1997). A él le siguieron algunos ensayos de un sociólogo de la Universidad Centroamericana en Managua, basados en observaciones y diálogos con pandilleros y pandilleras en un barrio y dos prisiones de esta ciudad (Rocha, 2000a, 2000b, 2003), y un estudio relacionado con la práctica social-comunitaria de la Fundación Desafíos en la ciudad de Estelí (Abaunza y Andino, 2002).

Las publicaciones de José Luis Rocha son parte de un, hasta entonces, proyecto único centroamericano de investigación en colaboración con cuatro institutos en El Salvador, Guatemala, Honduras y Nicaragua, y cuyos resultados fueron presentados en un volumen (Maras y pandillas en Centroamérica, 2001). Especialmente aclaradores resultan los nuevos estudios cualitativos sobre el problema en Honduras (Castro y Carranza, 2001) y en Nicaragua (Sosa Meléndez y Rocha, 2001), desarrollados a partir de intensivas observaciones y diálogos con pandilleros, cuyas biografías reconstruyen, realizadas en barrios de la ciudad hondureña El Progreso y de Managua. El estudio llevado a cabo en El Salvador de María L. Santacruz Giralt y José Miguel Cruz Alas (2001) se basa en discusiones de grupo con ex-pandilleros y pandilleros en activo, así como con familiares y vecinos, pero que no tuvieron lugar en estos barrios sino en la universidad. El estudio sobre el tema en Guatemala (Merino, 2001) se limita a resumir la investigación de AVANCSO de 1987, a valorar publicaciones de la prensa y a seguir las opiniones difundidas en la población.

Los cuatro estudios se caracterizan —a pesar de ceñirse, en parte, a diferentes métodos de investigación- por la interpretación en un contexto social y político amplio del fenómeno de las maras y las pandillas, así como de la violencia practicada por estas agrupaciones. Sin embargo, en sus interpretaciones —en comparación con publicaciones anteriores de algunos autores participantes (Cruz y Portillo Peña, 1998; Rocha, 2000a)— se establece una tendencia mecanicista en la explicación de los modelos que, a mi parecer, no aclara de manera adecuada la complejidad de las condiciones de formación de las maras y las pandillas ni los motivos y las autovaloraciones de sus actores. En vez de observar a las pandillas como una forma de vida con todas sus facetas, éstas son entendidas ex- clusivamente como "vehículos de violencia". Esto también vale para el estudio consecutivo del Instituto Universitario de Opinión Pública de San Salvador (Santacruz Giralt y Concha-Eastman, 2001) que contempla a las maras casi exclusivamente bajo el aspecto de las consecuencias negativas para la salud y la vida que conllevan.

Junto a las citadas investigaciones, me baso en este artículo también en estudios más pequeños, publicaciones periodísticas y ensayos, así como en experiencias y observaciones propias que he realizado desde 1984 en Nicaragua, Honduras, Guatemala y El Salvador. ${ }^{7}$

\section{HISTORIAY EXTENSIÓN DEL FENÓMENO EN LA REGIÓN ESTUDIADA}

En Centroamérica, así como en otras partes de América Latina, las agrupaciones de adolescentes y jóvenes se asocian, desde la década de 1960, con la imagen de las grandes ciudades. Surgen de manera proporcional al crecimiento de barrios y colonias marginales y se pueden entender como una consecuencia del desarrollo capitalista que destruye las formas de vida tradicionales y las bases de subsistencia agraria, sin aportar las bases de una existencia estable y menos aún de una vida mejor a las personas expulsadas del campo. Para los adolescentes y jóvenes que tienen toda una vida por delante, esto implica una exigencia muy grande (Liebel, 1992: 57-65). El fenómeno de las pandillas juveniles se puede vislumbrar como una respuesta colectiva de los jóvenes a su situación vital insoportable y como un desafío a una sociedad que les niega su participación y su futuro.

Hasta los años 1980 se trata de formaciones de vida relativamente cortas y con estructuras informales. En aquel tiempo se distinguen dos tipos de grupos. Uno está formado por jóvenes que se juntan en las esquinas de las calles de sus barrios para disfrutar, más allá del trabajo y de la escuela, de su tiempo libre, y que a veces —en re-

\footnotetext{
${ }^{7}$ Sobre Costa Rica encontré solamente informaciones rudimentarias; y sobre Belice y Panamá absolutamente ninguna fuente de información. En el diario La Nación (Arguedas y Segnini, 2000) se publicaron algunos comentarios de sociólogos de la Universidad de Costa Rica.
} 
lación con movimentos sindicales o estudiantiles- protestan en contra de situaciones anómalas (por ejemplo, el alza de las tarifas del transporte público). El segundo tipo son las agrupaciones de niños y adolescentes que, al menos temporalmente, viven en la calle y que se encuentran en determinados lugares para organizar su sobrevivencia. Estos últimos viven fundamentalmente de robos, de pedir limosna y de trabajos temporales.

Estos jóvenes no se identifican todavía - como las pandillas posteriores - con un barrio determinado, sino que están ocupados en primer lugar en encontrar sitios donde, temporalmente y de alguna manera, estén protegidos y puedan pasar la noche o su tiempo libre sin ser molestados. Conflictos entre estos grupos juveniles son relativamente raros a causa de su fugacidad, que no da cabida a que se originen sentimientos de pertenencia a un grupo. Por supuesto que hay enfrentamientos con la policía y los militares que persiguen a los jóvenes y que intentan acabar con la imagen que los vincula a la calle con métodos brutales que llegan hasta la eliminación física —en Nicaragua, durante los últimos años de la dictadu- ra de Somoza; en Guatemala, durante el régimen militar que se estableció en $1978 .{ }^{8}$

Aproximadamente a mediados de la década de 1980 cambia en parte el carácter de los grupos juveniles. Junto a los "grupos de esquina" y los de "niños de la calle" surgen y se extienden ${ }^{9}$ las pandillas en sí que, comparativamente, tienen nuevas formas de organización y diferentes maneras de actuar. Adquieren pronto un significado particular y un prestigio considerable entre los jóvenes del

8 En Nicaragua participaron muchos grupos callejeros en la resistencia contra la dictadura somozista y simpatizaban, al menos al principio, con la revolución sandinista que triunfó en 1979 (Liebel, 1992: 126-127; Cuerno, 2000: 71). En Guatemala, "hasta octubre de 1978 la calle tenía un significado muy especial para los jóvenes. En ella habían podido mostrar sus disgustos, manifestar sus pretensiones, ser ellos mismos. Detenciones arbitrarias y torturas en un inicio, desapariciones después, y finalmente la fuerza brutal de las armas de fuego, los habían hecho callar y retirarse de un territorio que consideraban propio" (Merino, 2001: 164).

${ }^{9}$ El desarrollo del fenómeno sucede de manera paralela al desarrollo del mismo en México (Gomezjara et al., 1987a, 1987b; Reguillo Cruz, 1995; Encinas Garza, 1994; Urteaga Castro-Pozo, 2000; Valenzuela Arce, 2002). Ya, incluso antes de 1985, había en Mexico y en parte de Centroamérica algunas pandillas con carácter territorial, pero apenas fueron tomadas en cuenta por la opinión pública. barrio. Estas pandillas sueltas congregan más jóvenes que los grupos de la calle que existían con anterioridad, de 40 a 50 integrantes, algunas llegan incluso hasta cien y más. Entre sus actores se encuentran sobre todo jóvenes que viven en los barrios y que se identifican con ellas. La defensa de los territorios delimitados por los jóvenes, algunas cuadras o todo el barrio, se convierte en uno de los elementos centrales para entender sus actos. Al contrario de los grupos de la calle que más bien evitaban llamar la atención en exceso, las pandillas hacen acto de presencia en la calle, en el vecindario y en las escuelas públicas de manera provocativa y llamando la atención (AVANCSO, 1988: 2). En Guatemala, y más tarde en El Salvador y en Honduras, toman el nombre de mara; ${ }^{10}$ en Costa Rica se designan a sí mismos como chapulines ${ }^{11}$ (Cuerno, 2000: 68).

El desarrollo de las pandillas en El Salvador, a causa de la guerra civil ${ }^{12}$ que duró largos años, sucede por etapas. Las maras aparecen en grandes proporciones en 1992, después del acuerdo de paz, y adquieren al mismo tiempo características particulares. En las primeras maras se juntan no sólo jóvenes de los barrios, sino también muchos antiguos guerrilleros y soldados desmovilizados que han quedado decepcionados con respecto a las esperanzas que tenían puestas en una vida mejor y en un reconocimiento social. Además, se integran también jóvenes que durante la guerra civil emigraron con sus familias a Estados Unidos, o que nacieron allí, de donde fueron de nueva cuenta expulsados. ${ }^{13}$ Las biografías y experiencias

\footnotetext{
${ }^{10} \mathrm{El}$ nombre de mara para referirse a estas agrupaciones fue utilizado primero por la policía durante una huelga contra el alza de las tarifas de autobús en la que participaron de manera activa las pandillas; éstas se lo reapropiaron para autodenominarse. El nombre viene probablemente de la película brasileña Marabunta, exhibida en aquel entonces en los cines.

11 También la expresión chapulín surge originariamente de la policía, con afán de subrayar el carácter delincuente de las pandillas; de una manera irónica, fue considerado apropiado por estas últimas. En la novela Los Dorados (Muñoz Chacón, 2000) se describe, con el lenguaje de los pandilleros, de manera muy sensible y gráfica, la vida cotidiana de las pandillas en los barrios de San José.

${ }^{12} \mathrm{Al}$ igual que en Nicaragua, en El Salvador muchos jóvenes de las ciudades también se incorporan a la guerrilla.

${ }^{13}$ Casi al mismo tiempo que el acuerdo de paz, en Estados Unidos se recrudeció la ley de emigración y en los años siguientes fueron deportados miles de jóvenes a El Salvador (así como a otros países de Cen-
} 
tan especiales de estos jóvenes conlleva que muchas maras en El Salvador se inscriban en una corriente especialmente violenta.

Las maras en las que los jóvenes provenientes de Estados Unidos llevan la voz cantante se caracterizan por ser especialmente grandes, rigurosamente organizadas y por actuar con armas de fuego. Las dos más conocidas son la Mara Salvatrucha (MS) y la Mara Dieciocho (M18).14 Sus miembros más activos y sus dirigentes pertenecían antes a los gangs del mismo nombre en Los Ángeles, conformados solamente por jóvenes latinos, los llamados chicanos. ${ }^{15}$ En El Salvador cada mara consta de una centena de miembros y su campo de acción no se limita a barrios particulares; están subdivididos en clicas locales, que actúan y se desenvuelven independientemente. Mantienen relaciones con maras en Guatemala y Honduras, algunas del mismo nombre, en las que se encuentran asimismo jóvenes que fueron deportados de Estados Unidos. ${ }^{16}$ Junto a estas maras organizadas conjuntamente en diferentes países, existen en El Salvador, así como en otros países de Centroamérica, las llamadas maras locales o maras de barrio, que tienen sus puntos de acción en los barrios locales. ${ }^{17}$

José Luis Rocha (2001), en una consideración comparativa sobre los nuevos estudios realizados en Centroa-

troamérica y a México) que se habían organizado en street gangs o que habían entrado en conflicto con la ley de otras maneras (De Cesare, 1998: 25-26).

14 Salvatrucha es una combinación de las palabras Salva = El Salvador y trucha $=$ un pez que se mueve contra la corriente simbolizando la sobrevivencia bajo circunstancias adversas. El nombre M18 se inspira en la 18th Street en Los Ángeles, uno de los campos preferidos de acción de las bandas de ese lugar.

15 Sobre el proceso de formación, las actividades y las formas de organización de las bandas de chicanos en Los Ángeles, véase Moore, 1991; Vigil, 1994, 2002; y De Cesare, 1998.

16 En el aeropuerto de la ciudad de México existe una especie de departamento internacional de maras. Allí son recibidos los que vuelven de manera obligada (homies) y donde son reclutados para incorporarse a algún grupo.

${ }^{17}$ Las maras y pandillas de las que se habla aquí deben diferenciarse de grupos de escolares que han surgido en algunas escuelas privadas (" $m a$ ras light"), que imitan a las maras y se llaman de igual manera y cuya meta principal estriba en la defensa del uniforme escolar. Del mismo modo, hay que disociar a las maras de ciertos grupos que fueron fundados con el único fin de realizar actos delictivos; esto pertenece al repertorio de actividades de muchas maras, pero no es el punto central de sus intereses (Cuerno, 2000: 701-702; Merino, 2001: 178).

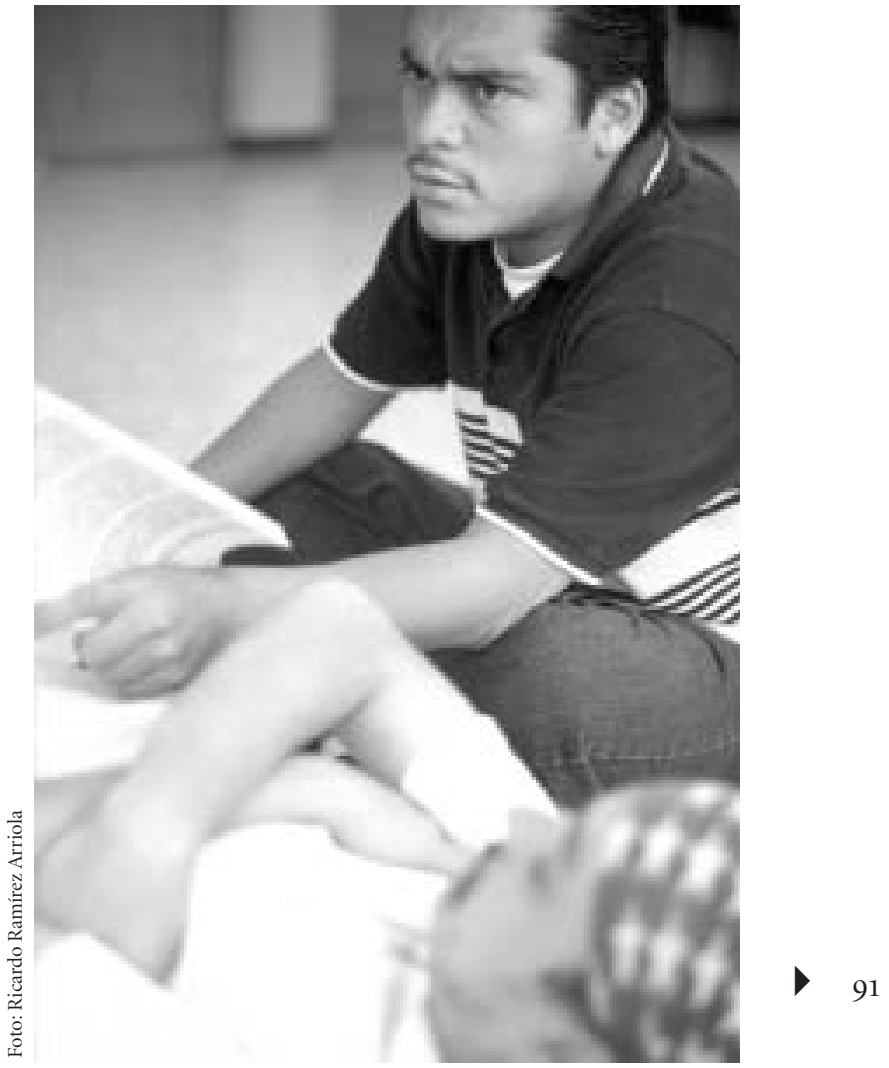

"Momentos alegres, un montón. Muchas veces el estar cerca de tus amigos, conversar, hacer una broma, reírse."

mérica (Maras y pandillas en Centroamérica, 2001), señala que las maras de El Salvador, Guatemala y Honduras, por un lado, y las pandillas en Nicaragua, por otro, presentan características diferentes. Las maras actúan de manera más profesional y agresiva que las pandillas en Nicaragua. Rocha atribuye esto a la gran represión estatal y paramilitar y a la fuerte influencia de Estados Unidos en los países nombrados en primer lugar. El hecho de que las estructuras de las maras sobrepasen las fronteras nacionales lo interpreta como una consecuencia de la globalización, hecho que en este contexto está muy influido por el narcotráfico internacional, mismo que incide y le da el tono al aumento de la violencia y al fuerte perfil delictivo actual de las maras en El Salvador, Guatemala y Honduras. En la ciudad de Guatemala, según estimaciones oficiales, debían de estar activos, ya en 1987, unos 28000 


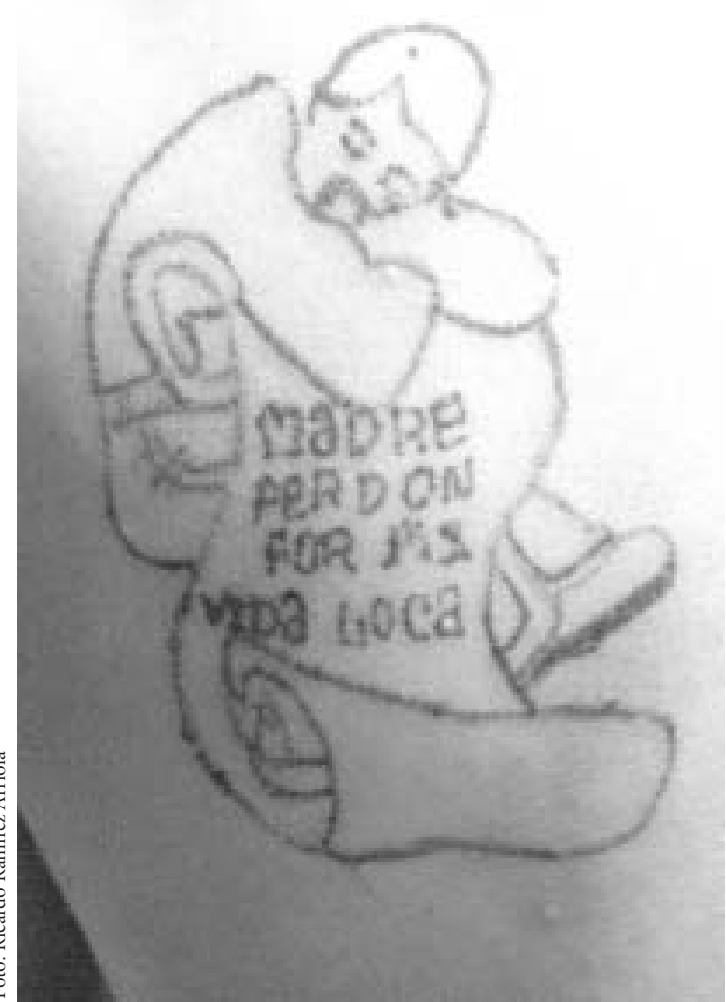

"Es el de la vida loca de uno en la calle y sus tres puntos. Uno es un hospital, el otro es una cárcel y el otro es un cementerio."

jóvenes (AVANCSO, 1988: 2), y desde entonces presentaban supuestamente una tendencia a aumentar (Merino, 2001: 167-168). En El Salvador, a finales de 1996 pertenecían a las maras por lo menos 20000 jóvenes (IUDOP, 1997: 695; De Cesare, 1998: 25); la gran mayoría se ubicaban en la capital, San Salvador. En el año 2000, las estimaciones son de 30-35 000 integrantes (Santa Cruz Giralt y Concha-Eastman, 2001: 13). En Honduras, la prensa local estima que en 1998 el número de mareros activos era de 60 000. Sólo en la capital, Tegucigalpa, había 151 grupos de maras con 14858 miembros (11 987 muchachos y 2861 muchachas) (Castro y Carranza, 2001: 237). En Managua, la capital de Nicaragua, la policía contó, a principios de 1999, 110 pandillas con una media de 75 miembros, lo que hace una suma total de 8250 pandilleros (Rocha, 2000a: 19). Rocha estima que el número real es más alto e indica que en algunos barrios de Managua la mayoría de los jóvenes se consideran pandilleros (op.cit:: 20). En Costa Rica se evalúa un desempeño numérico pequeño en los chapulines, pues están menos organizados de manera permanente (Krauskopf, 1996: 776; Cuerno, 2000: 68). Las cifras citadas se consideran sólo como aproximativas. Los organismos oficiales y la prensa suelen basarse en ellas para dramatizar el fenómeno y raramente se explican los métodos y los criterios en los que se basan esas estimaciones. José Miguel Cruz hace hincapié en que el fenómeno está hoy tan extendido que apenas es posible cuantificarlo (en Santa Cruz Giralt y ConchaEastman, 2001: 24). De lo que no cabe duda es que en las pandillas y en las maras de la mayoría de los países de Centroamérica participan actualmente un número grande de jóvenes que supuestamente tiende a aumentar.

\section{SITUACIÓNY CONDICIONES DE VIDA}

\begin{abstract}
Toda mi vida ha sido una cruz, pues mi papá es alcohólico y ahorita está tomando desde la Navidad y no hay modo que pare la furia, en cambio mi mamá es la mejor del mundo... y no sólo lo digo yo. Yo tengo una hermana y las dos sufrimos mucho porque mi papá no nos da dinero, ni para comer. Hoy llegó a las 5:00 bolo... Ah, pero mi abuelita que vive en los USA, ella sí nos quiere, ella nos ayuda, gracias a ella puedo estudiar (pandillera, según AVANCSO, 1988: 52).
\end{abstract}

Al contrario de la suposición muy aceptada de que las pandillas y las maras están integradas por jóvenes que viven en la calle o que fueron niños de la calle, en general las investigaciones resaltan que los jóvenes tienen su centro vital en los barrios y que allí, en su mayoría, disponen de un hogar, por precario y conflictivo que éste sea. En las investigaciones también se destaca que la mayoría de los pandilleros no se mantienen con hurtos y atracos, sino que después de abandonar la escuela ejercen un trabajo, mejor o peor pagado, o lo tratan de encontrar y que aparte de esto cuentan con una formación escolar que supera la media. ${ }^{18}$

${ }^{18}$ Los datos contenidos en este párrafo se refieren fundamentalmente
a Guatemala y a El Salvador y están tomados de las siguientes publica- 
En Guatemala, en la década de 1980, la mayoría de los mareros $(80 \%)$ tenía entre 15 y 19 años y ninguno era mayor de 25 . Se mostraba una cierta tendencia a que la media de edad descendiera lentamente y de que el punto central se situara entre los 12 y 15 años. En El Salvador de la década de 1990, la edad de la mayoría de los mareros $(72 \%)$ era semejante a la de Guatemala diez años antes, oscilaba entre 16 y 21 años. En el año 2000, los jóvenes al entrar en la mara tenían un promedio de 15.1 años (los muchachos) y 15.3 años (las muchachas). Actualmente, más de la mitad de los jóvenes entran en las maras entre los 11 y los 14 años.

Las maras, al principio, se componían principalmente de varones: $80 \%$ en Guatemala y $78 \%$ en El Salvador. Una encuesta posterior en Guatemala, que se considera representativa, da como resultado una cuota de chicas de 44\%. Hoy en día, en El Salvador se estima que la proporción de mujeres es de un tercio. ${ }^{19}$ El número de muchachas que se unen a las maras, o incluso las fundan, parece ir en aumento. Actualmente hay en ambos países (y supuestamente también en otros) una serie de maras en las que el número de chicos y el de chicas es casi equivalente. Aunque en la mayoría de los grupos, las chicas tienen una posición subordinada, hay algunas maras en las que ocupan posiciones dirigentes y son respetadas como líderes por los varones.

Las maras pasan una gran parte del tiempo en la calle, pero en la mayoría de los casos disponen de una casa. La mayor parte de sus integrantes pasa la noche en casa; en Guatemala 80\% lo hace, en El Salvador, 90\%. En este último país más de la mitad de los pandilleros viven en la casa de los padres $(52.7 \%)$, la otra mitad con la madre, algunos también sólo con el padre. Otros viven con amigos $(13.7 \%)$, con familiares (12.4\%), con su amigo o su amiga (8.7\%); el resto vive solo o con otros jóvenes. Es

ciones: AVANCSO, 1988 y 1993; IUDOP, 1997; Cruz y Portillo-Peña, 1998; De Cesare, 1998; Cuerno, 2000. Algunos datos sobre las pandillas en Honduras se pueden hallar en Boddiger, 2001 y en Castro y Carranza, 2001; sobre el fenómeno en Nicaragua, en Sosa Meléndez y Rocha, 2001.

${ }_{19}$ Boddiger (2001: 2) habla tomando como referencia un estudio no publicado de la Asociación Cristiana de Jóvenes (autores: José Acevedo y Mario Posas); en Honduras habría 88.2\% de chicos y $11.8 \%$ de chicas. digno de atención que una tercera parte tiene hijos; $38 \%$ de las chicas ya son madres.

En Guatemala no se encontraron analfabetos entre los mareros: $61 \%$ iba a la escuela primaria o a la secundaria y $38 \%$ la había abandonado. ${ }^{20}$ Claro que ninguno iba a una escuela privada, los llamados colegios, centros escolares de paga donde se ofrece una educación mejor. Todos los jóvenes a los que se les preguntó mostraban gran interés en su formación, pero pocos estaban contentos con su escuela. ${ }^{21}$ La mayoría de las instituciones escolares las consideraban aburridas e inútiles.

Muchas maras dan muestras de su descontento también en la escuela y a menudo deben abandonar el establecimiento educativo antes de tiempo a causa de su comportamiento rebelde. En el estudio de AVANCSO, los investigadores se declaran impresionados por la capacidad que tienen los mareros para comentar las circunstancias políticas y sociales, y establecen paralelismos entre ellos y los jóvenes activistas de los movimientos políticos de los años 1970.

También en El Salvador los mareros han sido casi todos alfabetizados (96.3\%) y muchos tienen una formación escolar por encima de la media. Casi la mitad (46.3\%) asistió a la escuela hasta el noveno grado y una tercera parte $(32.5 \%)$ hasta acabar el bachillerato. Como media, los jóvenes tenían cursados 8.4 años escolares, y los que de manera obligada tuvieron que volver de Estados Unidos incluso 10.21 años. Sin embargo, también el número de los que abandonaron la escuela antes de tiempo, sin ningún certificado, era relativamente alto. Cuando se hizo la encuesta la mayoría de los entrevistados se encontraban fuera del sistema escolar (75.9\%), hecho que los investigadores del IUDOP explicaban debido a que la escuela no ofrecía a los jóvenes ninguna oferta adecuada, no los motivaba a aprender y los excluía por motivos sociales. ${ }^{22}$

\footnotetext{
${ }^{20}$ Comparado con eso, iban a la escuela en la década de 1980 sólo $50 \%$ de los jóvenes entre 15 y 19 años que vivían en la ciudad.

${ }^{21}$ El gran interés en la formación, a la vez que el rechazo de la escuela existente, se documenta muy bien en el estudio de Ardila Pedraza et al., 1995; lo mismo sucede entre los jóvenes de las pandillas de Bogotá, la capital de Colombia.

22 En Honduras $85 \%$ de los pandilleros habían dejado la escuela antes de tiempo, según Boddiger (2001: 2).
} 
En Guatemala los mareros están mal pagados en los trabajos temporales que realizan y no trabajan regularmente. En general dan una parte de lo que ganan a los padres y contribuyen muy activamente en el sostenimiento de la familia. Pero también, si ellos toman de su sueldo lo que necesitan para sus necesidades, entonces la familia no se ocupa más de ellos. Cuidar a su familia les produce orgullo y les da cierto poder en el entorno familiar. Esto trae como consecuencia el mantenimiento de los lazos familiares, así como el distanciamiento de la familia, cuando es necesario. Un gran problema para ellos lo constituye, sin duda, la dificultad de establecer una casa propia.

En El Salvador, diez años más tarde, la situación de los jóvenes era considerablemente más complicada. Casi tres cuartos $(74.5 \%)$ de los encuestados no desempeñaban en el momento en que se hizo la encuesta ningún trabajo pagado, ${ }^{23}$ y de los pocos que tenían uno, sólo la mitad $(52.5 \%)$ disponía de un contrato de trabajo. El resultado ponía de manifiesto que sólo uno de diez jóvenes tenía un empleo más o menos seguro. Entre los que tenían un trabajo pagado, $28.4 \%$ se desempeñaba en algún tipo de oficio especializado (zapatero, corte y confección, panadero, etc.), $18.2 \%$ se dedicaba a oficios no especializados (ordenanza, empleada doméstica, etc.) y 12.9\% trabajaba como mecánico automotriz. Otros, en menores porcentajes, eran comerciantes, transportistas, empleadas de oficinas, empleados de servicio y carpinteros. La mayoría de los empleos no estaban en relación con el nivel de estudios alcanzado y eran mal pagados. El sueldo es tan pequeño e irregular que, por lo menos de vez en cuando, no les queda más remedio que cometer actividades ilegales, por ejemplo, vender drogas o robar, para conseguir lo necesario para vivir. ${ }^{24}$

Las familias de las que provienen los mareros viven, en la mayoría de los casos, en tal pobreza que no pueden alimentar adecuadamente a sus hijos y de ninguna manera ayudarles económicamente. A menudo el espacio de la casa es $\tan$ pequeño, que a medida que los niños se hacen

\footnotetext{
${ }^{23}$ En la investigación del IUDOP, la mitad de los encuestados manifestaron que el mes anterior habían buscado en vano un trabajo.

${ }^{24}$ En Honduras estaban, según Boddiger (2001: 2), en el momento de la encuesta (2000), $45 \%$ de los encuestados sin trabajo.
}

mayores no cuentan con ningún espacio propio y los jóvenes prácticamente deben irse a la calle. Para éstos no existe ninguna organización estatal o comunal donde, sin pagar y según sus gustos, puedan pasar su tiempo o hacer cosas de interés. Tienen que recurrir a establecimientos comerciales que cobran por el servicio.

Algunos mareros están solos porque sus padres o sus hermanos mayores han emigrado definitiva o temporalmente a Estados Unidos. En el estudio de Lorena Cuerno (2000: 64) se puso de manifiesto que nueve de cada diez jóvenes salvadoreños entrevistados tenían familia en Estados Unidos, sin que fueran directamente ayudados económicamente por ella. Contaron que esos familiares ocasionalmente, cuando los visitaban, les traían ropa, videos, equipos de sonido, discos compactos u otros objetos de consumo, que vendían para poder sobrevivir o para comprar drogas.

\section{ACTUACIÓNY PREFERENCIAS}

\begin{abstract}
La calle le enseña a uno a vivir o morir y, pues, uno tiene que aprender a rifársela (pandillero, según Cuerno, 2000: 67).

Sólo Dios sabe por qué me tocó andar por estos barrios. Se cansa uno de la "vida loca". Pero a veces es inevitable. No hay nada que hacer. Y uno se mete o se mete... se empieza a vaci[lar] - "brincan" [pelean] a uno y ya. Yo vivo en la calle desde los nueve años y es mejor andar con la "mara" que solo. Aunque como mujer es más dificil” (pandillera, según Cuerno, 2000: 63).
\end{abstract}

En el centro de la mara o pandilla está lo que los jóvenes llaman "la vida loca": la sensación que trae la lucha de la propia banda con bandas rivales de otros barrios, con otros jóvenes que se creen más que ellos ("burgueses") o con la policía; en Nicaragua se le llama la cateadera. Lo que les motiva es el gusto por la provocación y el no siempre calculado riesgo de hacer cosas consideradas escandalosas por los ciudadanos "normales" o que claramente están prohibidas. Lo que más les gusta de la vida en las pandillas es lo que en las maras de El Salvador se llaman los vaciles. Esto puede significar cualquier cosa: desde las buenas vivencias en la pandilla y el sentido de pertenencia hasta 
las actividades situadas al límite de lo legal o fuera de la ley, la acción —expresión a la vez del mundo de los pandilleros y pandilleras con sus aspectos buenos y malos, de los que ellos también tienen conciencia.

La mayoría de los pandilleros roban y consumen drogas (sobre todo marihuana y alcohol, y de manera más reciente, también con frecuencia crack). Estas actividades, que la prensa y los políticos reprueban y destacan como típicas de las bandas de jóvenes, no constituyen una característica exclusiva de las pandillas y maras, sino que están bastante extendidas entre todos los jóvenes. Las drogas son parte de la vida cotidiana de las pandillas, pero no son ni la causa ni el motivo para estar juntos. En los robos y atracos no participan en absoluto todos los pandilleros $\mathrm{y}$ - esto me parece importante destacar- se practican raramente como pandilla. Las actividades prioritarias que el grupo realiza como pandilla o mara son las peleas, los pleitos, las luchas llevadas a cabo de conjunta. Esto une a todos los pandilleros y pandilleras que, por cierto, casi nunca van a pelear bajo el efecto de las drogas. ${ }^{25}$

La participación en las peleas y las habilidades y el valor demostrado son decisivos para alcanzar el reconocimiento social y la posición de los pandillleros y los mareros dentro del grupo. Les otorgan perfil y prestigio. La filosofía de los que luchan es actuar rápida y avispadamente antes de que el otro se adelante, y dominar la situación en la medida de lo posible. Lo decisivo es "andar sobre", y de ninguna manera dejarse "achantar".

El punto de referencia en la actuación de los pandilleros es sobre todo el barrio en el que el pandillero ha crecido, donde se siente en casa y de alguna manera seguro. Allí será también, en determinadas circunstancias, considerado como enemigo (por ejemplo, por adultos que se ocupan de la buena reputación de su barrio), pero también encuentra simpatía y ayuda (por ejemplo, de su madre) y se mueve en terreno conocido. La pertenencia al barrio le aporta un sentimiento de identidad, al igual que la pandilla. Por eso no es ninguna casualidad que las

${ }^{25}$ En Honduras se informa que en algunas maras hay una prohibición interna de uso de ciertas drogas. En las maras de la ciudad de El Progreso no hay en general ninguna obligación de consumir drogas (Castro y Carranza, 2001: 292-293). luchas de las pandillas se desaten en defensa de un territorio que se circunscribe al barrio o a las cuadras cercanas. Esto puede significar también que en el mismo barrio —normalmente en oposición a adultos que rechazan a los jóvenes o que los tratan con hostilidad - se luche por la supremacía. Dice un pandillero de un barrio de Managua: "Nosotros gobernamos el barrio sin que nadie nos diga nada. Si alguien nos dice algo, lo palmamos. Se acalambran porque somos muchos. Los jóvenes mandamos" (pandillero, citado por Rocha, 2000a: 23).

Jose Luis Rocha, de la Universidad Centroamericana de Managua, da la siguiente interpretación: "La reacción del pandillero en un mundo en el que él no es nadie es atacar, dominar el barrio, someter porque está sometido, demarcar un territorio porque vive en el desarraigo,

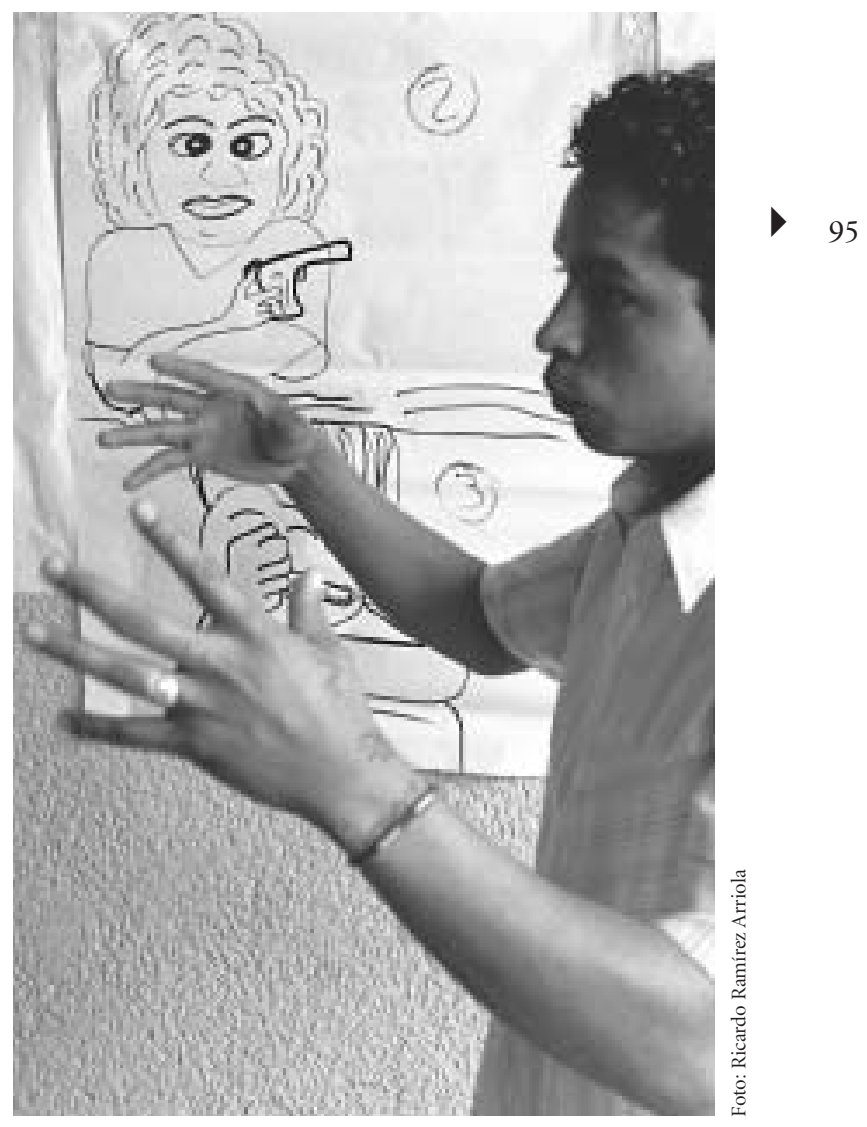

"Aunque ande todo marcado a mí no me importa. Ahora sé que soy una persona que valgo bastante y sé que voy a ayudar a otros homies." 
asociarse a una institución que dota de identidad porque se carece de ella. El pandillero aspira a dominar en un entorno que lo excluye" (Rocha, 2000a: 23).

En El Salvador (Cruz y Portillo Peña, 1998; Santa Cruz Giralt y Concha-Eastman, 2001) se preguntó a los jóvenes sobre lo que les gustaba de la mara y las ventajas que conlleva. Nombraron a los vaciles, ya mencionados arriba, como la parte atractiva, es decir, la acción conjunta al borde y al otro lado de la legalidad; el compañerismo entre los bróderes; el respeto que han ganado, además del poder, protección, unión entre los bróderes, confianza interpersonal, dinero, libertad de los padres y, en menor medida, los pleitos, las hainas (mujeres) y las drogas.

Entre las cosas que menos les gusta de la mara, nombraron en primer lugar, otra vez, las peleas y las drogas, sobre todo los chambres y los cortos. Como desventajas que conlleva la vida en las maras destacaron, más que nada, la discriminación (a través de externos) y la persecución de la policía, así como el peligro de ser encerrados en la cárcel o el ser asesinados.
Las consideraciones sobre la vida en la mara cambian, por cierto de forma llamativa, de los chicos a las chicas. Estas últimas nombraron frecuentemente como aspecto negativo el trencito, la práctica de ofrecer servicios sexuales —en parte exigido por el jefe de la pandilla— a los miembros masculinos de la banda. Los típicos distintivos de la vida en la mara son en general considerados más negativos por las jóvenes mujeres que por sus compañeros masculinos. Las chicas destacan como aspectos atractivos para ellas, principalmente, el "pasar buenos momentos juntos" y "la ropa".

Como ya se hizo en el estudio guatemalteco de la década de 1980 (AVANCSO, 1988), en las investigaciones salvadoreñas (Cruz y Portillo Peña, 1998; Santacruz Giralt y Concha-Eastman, 2001) también se desmiente la concepción difundida de que los jóvenes huyen de los problemas y deficiencias que sufren en sus familias. Los jóvenes se incorporan a las maras sobre todo porque la vida allí es más atractiva y tiene, desde su punto de vista, más ventajas que desventajas. A pesar de las dificultades

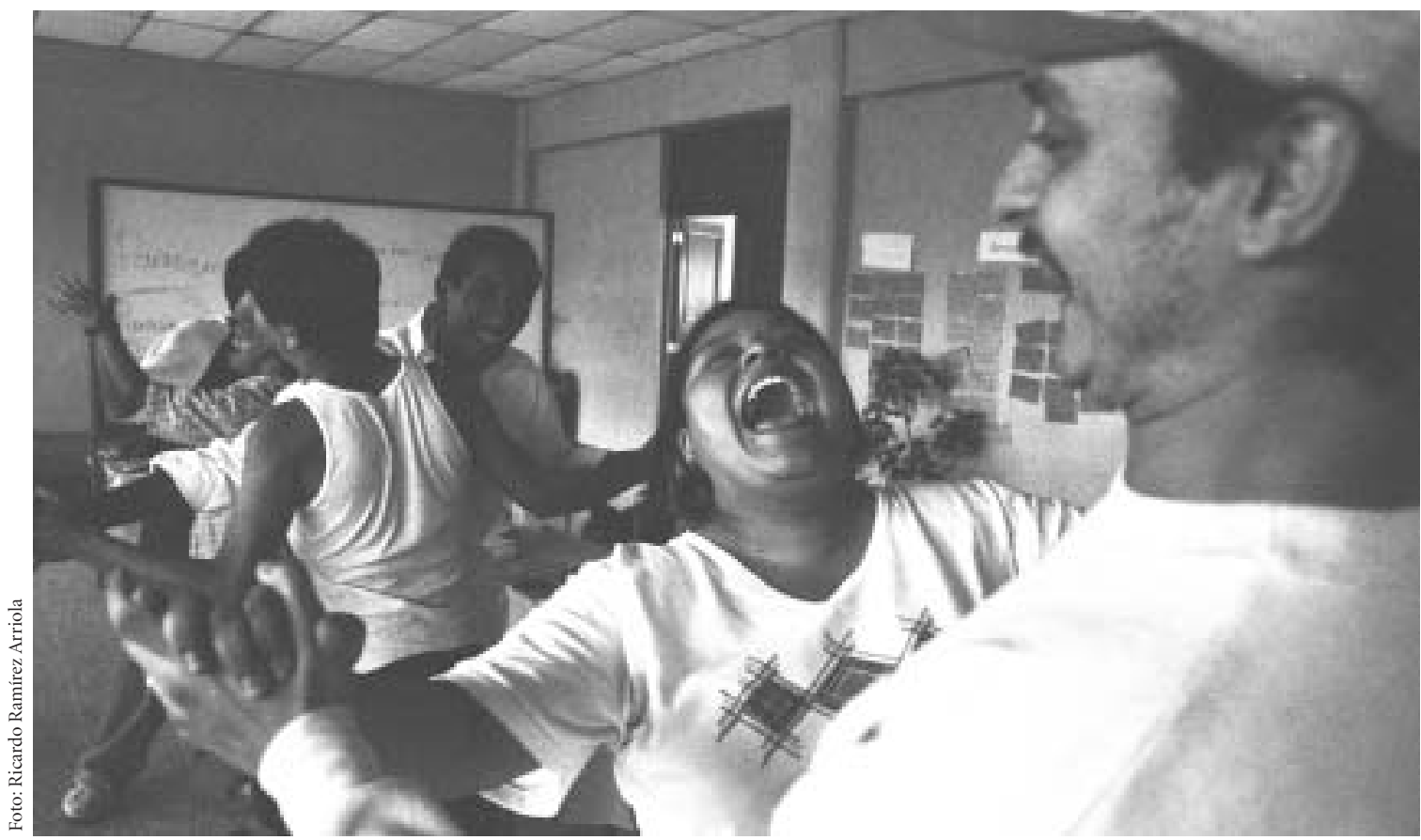

"Ahora diario voy a trabajar. Saludo a gente que me estima que yo no conocía y que me da un abrazo y me siento bien alegre, pues. Todos los días es un reto más para mí.” 
y los peligros, ven más satisfechas sus necesidades físicas en todo lo que pertenece y conlleva la mara, que en otros lugares accesibles para ellos. Esto sobre todo porque en las maras son tomados en cuenta y considerados como importantes. Otro estudio salvadoreño llega a la conclusión de que para muchos jóvenes "las maras son una red social que les proporciona ingresos, autoestima y solidaridad" (Cuerno, 2000: 63).

\section{CONVIVENCIAY CULTURA JUVENIL}

En la mara se aprende un resto de cosas, entre ellas a ser bien pero bien BIEN honesto. Por ejemplo, usted tuvo cacha con otros dos carnales (amigos) y cayeron 200 varas (quetzales). Se reparten iguales y lo que no se puede repartir es para la trama (comida) en partes iguales hasta que se acaba (pandillero, según AVANCSO, 1988: 54).

Hay una hermandad dentro de la mara que en ninguna institución, en ningún partido político ni en ninguna otra parte tienen... Los demás no comen del mismo plato y nosotros sí comemos del mismo plato, nos tapamos con la misma cobija..." (pandillero, según Santacruz Giralt y Cruz Alas, 2001: 40).

La convivencia en la pandilla crea una historia común, un intercambio permanente de conocimientos y posibilita a los jóvenes encontrar reconocimiento y confirmar y fortalecer su nexo de amistad. La pandilla no surge para romper las leyes, sino como grupo de amigos que quieren hacer algo juntos. La fidelidad más grande es la de los bróderes de la pandilla, no la de la familia. La pandilla se convierte en una especie de familia "de forma real en el amor y las relaciones y no sólo retóricamente" (AVANCSO, 1988: 27 ), pues los miembros de la banda responden sin condiciones los unos de los otros y se defienden de cualquier agresión externa.

En el grupo se estima mucho la justicia y la honestidad, consideradas como cualidades de mando. En todas las pandillas existe una especie de código de honor, cuyo cumplimiento es absolutamente obligatorio para todos. Éste se entiende como una respuesta a la hipocresía que han experimentado los adultos y la corrupción de la sociedad. Casi ningún pandillero se deja comprar a cambio de promesas o regalo de dinero, por ejemplo, como espía de la policía.

Cada pandilla tiene sus rituales y sus reglas de funcionamiento. Siempre se refieren a la igualdad en el grupo, pero también pueden ser más o menos jerárquicas. Casi siempre hay jefes de pandillas que pueden dar instrucciones, pero sólo son reconocidos mientras demuestren las cualidades que favorecen al grupo y negocien en interés y en favor de toda la pandilla.

El ritual de admisión posibilita reconocer si el miembro es capaz de cumplir los requerimientos del grupo. Sobre todo son importantes los requerimientos para la pelea, la fuerza corporal, habilidad, rapidez de reacción y el estar preparado a no rajarse ante los peligros. La mara Salvatrucha, por ejemplo, elige unos cuantos compañeros que durante los 13 segundos iniciales le pegan y esperan de él que se sepa defender (en la mara Dieciocho son 18 segundos). La mara Morazan exige a los nuevos miembros que lleven a cabo una pelea con cuchillos con el jefe de la pandilla a fin de medir su astucia y habilidad, y sobre todo para reconocer que no temen involucrarse en disputas duras.

En el caso de las mujeres, el ritual de admisión comporta una variación. También se les exige que lleven a cabo peleas con otros, pero también existe la práctica ya mencionada del trensito, del estar dispuesta a tener relaciones sexuales con los varones del grupo. Una chica cuenta: "Una vez yo andaba bien loca, y cuatro batos de la clica me dijeron que me soltara la greña, yo les dije que no, que para eso me había brincado a golpes, y uno de ellos me dijo: mira loquita si no soltás te vamos a descontar, mejor que sea por las buenas. Y pues yo bien drogada, ¿qué hacía? Ni modo, ya me tocaba y pasaron los cuatro por mí" (citado por Cuerno, 2000: 69). Después de un ritual así, la chica es admitida y tiene que padecer más ataques parecidos. Pero por encima de todo, en sus propias maras, se espera que las mujeres tengan la misma respuesta que los varones en las peleas con otras pandillas, con la policía o al vacilar, es decir, involucrarse en acciones al borde de lo legal.

El trato irrespetuoso de los chicos con las chicas es desde luego también en las maras punto de disensión y da lugar a discusiones. Además, no se practica de la forma 
descrita en todas las pandillas. Hay maras en las que se niega de forma expresa el reparto normal de roles, discriminatorio para las mujeres, existente en la sociedad y en las que las mujeres ocupan una posición de igualdad e incluso llevan la voz cantante. ${ }^{26}$ Esto, por lo demás, vale también para la homosexualidad. Mientras que en Centroamérica la homosexualidad es considerada generalmente como anormal y como una enfermedad, en muchas pandillas se practica de manera abierta entre las chicas, así como entre los chicos, y no es de ninguna manera motivo de discriminación. En el estudio de AVANCSO, la mitad de las mujeres reconocieron haber tenido relaciones lésbicas, lo que por otra parte no excluye el mantener relaciones con hombres.

También las pandillas y maras crean desde el punto de vista cultural su propio mundo, que se diferencia y separa explícitamente de la sociedad "normal". Crean (como se ve claramente en las citas mencionadas) un lenguaje propio que sólo se entiende dentro del mundo de las pandillas. En él se mezclan frecuentemente palabras del español y del inglés, aunque tambien se recurre a versiones del español que eran usuales en tiempos pretéritos (el malespín) o que se utilizan en otros países de América Latina, sobre todo en México, Colombia y Venezuela. Al mismo tiempo son creadas nuevas palabras llenas de gracia e ironía. ${ }^{27}$ Además, está el lenguaje escrito, los graffitis y placazos, que a menudo sólo son comprendidos por los pandilleros, y que con frecuencia sirven para demarcar el territorio o transmitir determinados mensajes. Del mismo modo, el lenguaje simbólico de los tatuajes (Rocha, 2003) y de la pintura en las paredes, así como un determinado estilo en los gestos del lenguaje corporal, queda reservado para la comunicación al interior del grupo.

Las preferencias musicales abarcan un gran espectro, desde la música romántica y melancólica en español

\footnotetext{
26 Sobre las maras que se componen exclusivamente de mujeres informa Merino (2001: 172 y 190), se llaman a sí mismas Las Guerreras y Las Gatas.

27 Roger Matus Lazo (1997) recopiló, sólo en Nicararagua, más de 1500 palabras y analizó su origen y significado. Para nombrar a la policía existen más de 20 términos; para droga, más de 70. A la pandilla misma se le llama también machada. Sobre el lenguaje de las maras en El Salvador, véase Cuerno (2000: 72).
}

(cumbia colombiana, por ejemplo) hasta el rock inglés, y sobre todo el rap/hip hop (break dance) y la música heavy metal y punk. Pero también sus gustos sobre cantantes pueden ir desde El Puma hasta el extremo opuesto de Santana y Rod Stewart, desde Tina Turner hasta Tatiana, y grupos como Timbiriche están entre sus favoritos. A algunos mareros les gusta el instrumento tradicional de la marimba, que proviene de la tradición indígena. Al contrario de México (Reguillo Cruz, 1995), en Centroamérica es raro que las pandillas formen grupos musicales, creen letras de canciones o un estilo musical propio, pero están muy receptivas a esas cosas, como lo demuestra la iniciativa de la cantante de rock Lorena Cuerno en El Salvador.

\section{VIOLENCIAY DESEO DE JUSTICIA}

\begin{abstract}
Con violencia fui implantando respeto. Antes nadie me respetaba porque era pobre. Pero yo me hice respetar, y es muy importante ganarse el respeto (pandillero, según Rocha, 2000a: 24).

Hay muchas personas que son incrédulas [de tus buenas intenciones]. Sólo porque ven que pertenecés a una pandilla piensan que eres del todo malo. Pero no es así. Si te sentís muy querido y apreciado por los de tu comunidad, sentís también un gran aprecio por ellos, hasta querer dar tu vida para salvarlos de cualquier peligro y hacerles favores sin esperar ninguna recompensa" (pandillero de los Vatos Locos, según Castro y Carranza, 2001: 318).
\end{abstract}

La violencia psíquica y los enfrentamientos armados desempeñan actualmente un papel central en las maras y pandillas; pero aunque muchos mareros y pandilleros cometen actos ilegales y no toman en cuentan las leyes, sería quedarse muy corto el considerarlos como una subcultura criminal. "La mayoría de ellos poseen razones para estar en las pandillas que van más allá del simple interés en involucrarse en situaciones delictivas" (Cruz y Portillo Peña, 1998: 164). Las maras deben entenderse más como una variante de la cultura de sobrevivencia de los pobres y de los rechazados y un reflejo de la violencia extendida y practicada por todas partes en América Latina (Castillo Berthier, 1994; Fournier, 2000). 


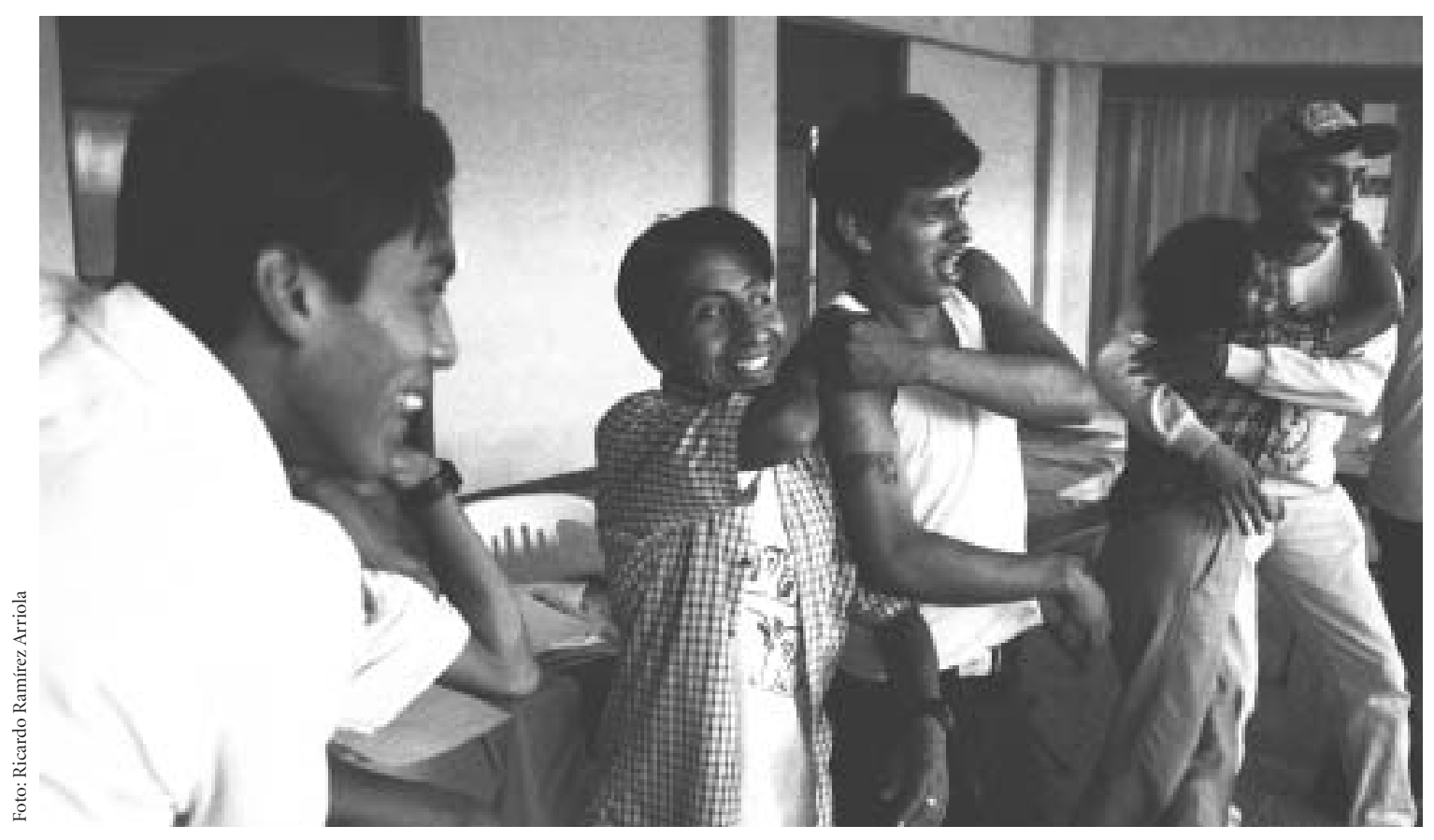

"APREDE fue el primero que logró meter en un mismo círculo a las dos pandillas con el único deseo de cambiar."

El sociólogo salvadoreño José Miguel Cruz, en un estudio sobre las formas y causas de la violencia en El Salvador, habla de una "cultura de la violencia". Esto lo entiende como "la creación de valores y normas que legitiman y conceden un privilegio al uso de la violencia en cualquier ámbito frente a otras formas de comportamiento social" (Cruz, 1997: 980). Desde el acuerdo de paz en El Salvador en 1992, se mueren al año 8000 personas por actos violentos, esto significa unos 140 muertos por cada 100000 habitantes. En América Latina son asesinadas 140 ooo personas al año, sin contar los cientos de miles que mueren antes de tiempo porque sufren de hambre o que viven en condiciones que afectan su salud. Por año, 28 millones de familias son víctimas de robos y atracos, casi una por segundo. Este tipo de violencia es en Latinoamérica cinco veces más alto que en el resto del mundo (Rocha, 2000a: 19). El aumento de la violencia no es solamente una consecuencia de la pobreza, sino que tiene su origen en la creciente desigualdad social que provoca en muchas personas la sensación de ser tratados injusta e indignamente, y crea desesperación y rabia.
Las neoliberales "medidas de ajuste estructurales" que fueron impuestas por el Fondo Monetario Internacional (FMI) y otras instituciones de finanzas internacionales en los países de América Latina desde el golpe militar chileno de 1973 y muy complacientemente ejecutadas en ventaja propia por las prevenidas y corruptas "élites" nacionales, son en sí mismas una forma de violencia estructural. Éstas no solamente han aumentado la pobreza, sino que están produciendo cambios culturales fundamentales. Dichos cambios están deformando la imagen que las personas tienen de sí mismas y sometiendo su modo de vida a nuevos estándares, mismos que no podrán ser satisfechos a causa de la situación de vida de las personas. La posesión de dinero, el hacer fortuna, el adquirir bienes de consumo llegan a ser las características prioritarias de una vida deseada y considerada estupenda, por lo que hay que conseguirlo cueste lo que cueste. "Valores que hasta ahora habían hecho más fácil la vida en común, como solidaridad, integridad, lealtad, entran necesariamente en contradicción con el nuevo sistema axiológico, ya que éste los muestra como poco eficientes y 
poco apropiados para competir (Fournier, 2000: 152). En consecuencia, se entierra la pertenencia social y las relaciones de confianza entre familiares, amigos y vecinos se ven sometidas a una dura prueba y a menudo son destruidas.

Los jóvenes viven el desmoronamiento de la cohesión social y la violencia de maneras distintas, mucho antes de unirse a una pandilla. Ya de niños tienen la experiencia de ver a su padre o padrastro de mal humor, irresponsable, violento y malo. En muchas familias el consumo de alcohol se vuelve crónico, producto del esfuerzo excesivo y de la desesperación. En El Salvador, una investigación dió como resultado que $80.5 \%$ de los encuestados fueron maltratados cuando eran niños. Casi la mitad ha vivido situaciones en que las mujeres y los niños eran insultados y amenazados regularmente (Cruz y González, 1997). El estudio de AVANCSO subraya que a menudo lo que les hace a los jóvenes la vida difícil no es la fragmentación de la familia, sino el comportamiento angustioso

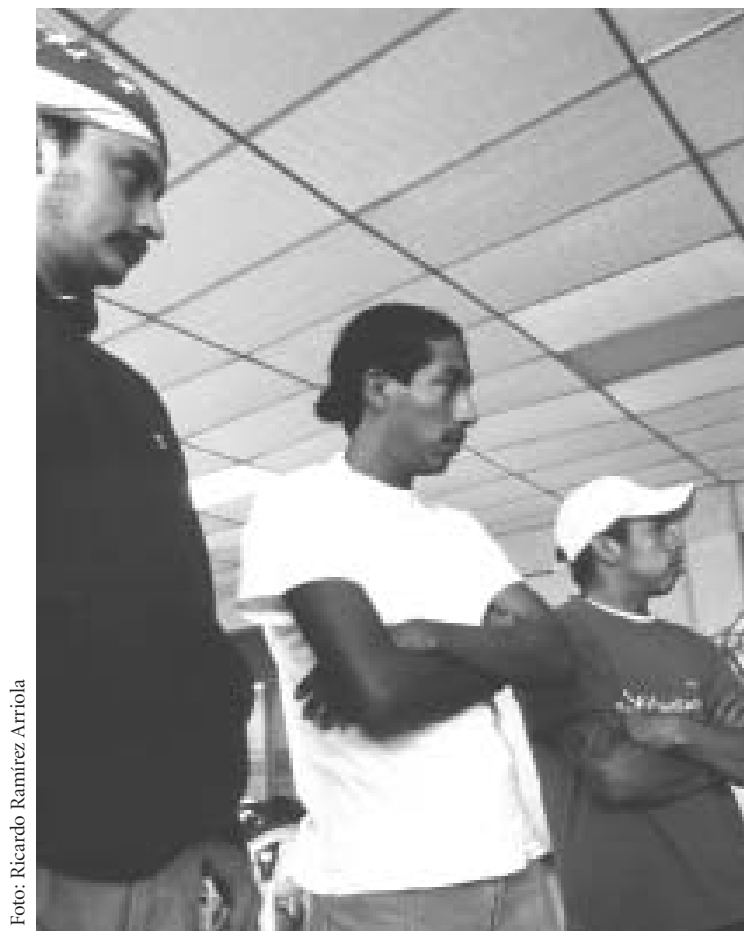

"La perspectiva con que miran a la pandilla tiene que cambiar porque no todos somos iguales. Hay que llegar a la raíz para saber entender." e inseguro de los adultos y la imposibilidad de comunicarse con ellos y poder desarrollar una relación de confianza (AVANCSO, 1988: 20). También en El Salvador, en la nueva investigación del IUDOP, se rechaza claramente la extendida "hipótesis simplista" de que los mareros provienen de "hogares desintegrados" (Santa Cruz Giralt y Concha-Eastman, 2001: 67), pero se destaca — como lo hacen otros estudios - que la vida familiar de los pandilleros está impregnada de violencia y falta de entendimiento. Sobre todo en las chicas es esa experiencia el motivo que las empuja a unirse a una mara.

Los jóvenes viven la violencia y la injusticia día a día en la calle, en la escuela, al buscar un empleo, en el trato con las autoridades estatales. En la escuela son discriminados y menospreciados por profesores que están sobrecargados de trabajo y mal pagados. La búsqueda de trabajo es como un callejón lleno de golpes y cuando excepcionalmente encuentran uno remunerado tienen que contentarse con un salario miserable, insuficiente para satisfacer sus necesidades vitales. Sólo a causa de tatuajes, de ropa inusual o del lugar donde viven son considerados por las autoridades estatales o por los autodenominados "escuadrones de la muerte" y otros grupos paramilitares como delincuentes potenciales o de hecho, y son objeto de vejaciones, amenazas y frecuentemente incluso asesinados. Por la mínima causa son detenidos por la policía y maltratados, las chicas a menudo violadas.

Al unirse a una pandilla, la mayoría de los jóvenes está convencida de que viven en un mundo injusto y de que ellos son los que padecen la injusticia. Integrarse a la mara es vivido como una venganza contra este mundo que les hace daño. Ante sus ojos hay gente rica que se aprovecha a su favor de los demás y gente pobre que es exprimida y que debe aguantar demasiado. Piensan que la sociedad no sirve a los pobres y los jóvenes, y no quieren tener nada que ver con ella. "Sociedad, en eso yo no tomo parte", dice un marero en Guatemala (citado por AVANCSO, 1988: 28).

A partir de su experiencia de la pobreza y de las amenazas, los mareros saben que deben actuar juntos para no hundirse. Pero no son políticamente radicales, en el sentido de que quieran cambiar la sociedad que consideran hostil e injusta. En primera línea ellos se defienden a 
sí mismos y quieren asegurar la parte del pastel que les corresponde, aunque sea por medio de la violencia. Más allá de la innata apropiación de bienes para atender necesidades inmediatas, por la miseria en que viven, las pandillas representan "una actitud contestataria de quienes han quedado en situación de marginalidad material o espiritual en el sistema, es decir, sin posibilidades reales para concretar y realizar un proyecto de vida válido y digno" (Escobar, 1996: 336).

Los jóvenes al integrarse a una pandilla manifiestan que a ellos la sociedad les niega las oportunidades educativas, culturales y económicas para desarrollarse como personas y vivir una vida satisfactoria. De ninguna manera idealizan su "vida loca" y dan muestras de un comportamiento ambivalente en relación con su manera de actuar, ${ }^{28}$ pero no ven otra posibilidad de vivir su vida $y$ afirmar una identidad propia. Ellos ven en sus actos criminales y en la violencia que practican un medio legítimo para satisfacer sus necesidades básicas, emocionales y materiales, y conservar un cierto nivel psíquico y económico. ${ }^{29}$

Para ellos es mejor sentirse importantes y valorados bajo circunstancias peligrosas, que ser "nada" o "nadie", según lo señalan Cruz y Portillo Peña (1998: 145) en su intento por desentrañar los motivos y las sensaciones de los mareros. El adolescente en particular "se encuentra en una mejor situación como miembro de una mara que como adolescente en el barrio, teniendo en cuenta consideraciones que son importantes para él. La decisión de hacerse miembro de una mara puede ser decisiva para el adolescente debido a que los beneficios son mayores que los costos [...], pero también la necesidad de acción, prestigio y estatus, dinero (obtenido o no de forma delincuencial), drogas, la atención de las chicas, son todas

\footnotetext{
28 La investigación del IUDOP llega al resultado "paradójico" de que lo que a los jóvenes "les atrae de las pandillas, parece ser lo mismo por lo que las quieren dejar. Parece que los jóvenes tienen claro que su futuro no está en las pandillas" (IUDOP, 1997: 710). Véase también la interpretación de pandilla como "cárcel cultural" (Rocha, 200ob).

${ }^{29}$ Rocha (2000a: 24) llama la atención de que en una vida oprimida y sin esperanzas, en la que el suicidio está presente como un peligro permanente, la vida de pandillero puede significar enfrentarse a la muerte y el intento de solucionar un conflicto - hasta ahora muy poco investigado-psíquico-existencial.
}

necesidades que pueden ser satisfechas dentro de la mara"30 (Savenije y Lodewijkx, 1998: 127, citado por Santacruz Giralt y Concha-Eastman, 2001: 114).

La pertenencia a una pandilla se entiende, finalmente, como intento de restablecer un espacio social que se ha perdido o que en la vida "normal" es inalcanzable. Los jóvenes intentan con la pandilla "crear una sociedad para ellos mismos en medio de una donde no existe nada adecuado a sus necesidades. Lo que los jóvenes obtienen por medio de las actividades de la pandilla es lo que les es negado en el mundo de los adultos: protagonismo"31 (Rocha, 2000a: 20).

Bajo contextos políticos y sociales diferentes muchos jóvenes que están en las pandillas desde la década de 1980 habrían encontrado probablemente otras formas de expresión menos violentas y destructivas o se hubieran unido a movimientos sociales dirigidos en aras de cambiar sus circunstancias de vida. Pero actualmente no es "el tiempo de movimientos comunales" y apenas existen alternativas políticas. También las organizaciones consideradas progresistas tienden a valorar a los jóvenes de acuerdo con los estereotipos extendidos por los medios de comunicación masivos y las instituciones policiales y rechazan a los pandilleros por lúmpenes e incluso luchan contra ellos colaborando con la policía (AVANCSO, 1993; Castro y Carranza, 2001: 316). Sin embargo, lentamente se extiende el reconocimiento de que muchos jóvenes que forman parte de pandillas están del todo receptivos a soluciones alternativas a sus problemas, bajo las condiciones previas de ser tomados en serio como personas autónomas, ser respetados y ser apoyados para terminar con la violencia experimentada por ellos mismos, con el desprecio hacia sus derechos y su dignidad. ${ }^{32}$

\footnotetext{
${ }^{30}$ Considerado desde el punto de vista de un marero masculino.

${ }^{31}$ Para el debate sobre el protagonismo de niños y adolescentes en América Latina, véase Liebel, 1994; Liebel, 2000 y los aportes en Liebel, Overwien y Recknagel, 2001.

32 Sobre esta práctica, hay en México una serie de ejemplos (Gomezjara, 1987b; Serna Hernández, 2000). También en algunos países de América Latina hay desde hace poco tiempo proyectos parecidos - la mayoría en un contexto de práctica comunal y cultural de barrio-que se desarrollan con la activa cooperación de pandilleros, en los que se busca alternativas a la violencia y se posibilitan experiencias distintas.
} 


\section{CONCLUSIONES}

Maras y pandillas juveniles no son una característica específica de México y Centroamérica. Se extienden también en las regiones más al sur del continente que no están vinculadas en la misma medida con Estados Unidos por los movimientos de migraciones y remigraciones. Aunque las influencias de las pandillas juveniles estadounidenses no se pueden pasar por alto, las pandillas no surgen imitándolas simplemente, sino que tienen sus propias raíces en las condiciones sociales y las culturas de América Latina.

Su rápida extensión por esta región del mundo indica que no se pueden contemplar como un modelo en vías de extinción, condenado a desaparecer con la "modernización" del continente. Surgen como parte de las estrategias de supervivencia y de los intentos prácticos de enfrentarse a los crecientes riesgos de vida. Trasmiten a los adolescentes la sensación de actuar por su propio gusto y de ser dueños de sus vidas. Son tanto expresión como condición para que los adolescentes se sientan como seres - a pesar de los riesgos vitales que implican- lo suyo para que los jóvenes obtengan una parte del poder de definición, negado hasta hoy en día por una sociedad autoritaria y sin escrúpulos.

La pandillas juveniles, según la hipótesis de la antropóloga mexicana Rossana Reguillo, también se pueden entender como un "termómetro para medir los tamaños de la exclusión, la brecha creciente entre los que caben y los que no caben, los inviables, los que no pueden tener acceso a este modelo y que por lo tanto no alcanzan el estatuto ciudadano" (Reguillo, 2000: 124). La autora invita a reconocer el comportamiento de los jóvenes hacia fuera y sus relaciones con otros como "formas de pro-

Son descritos en El Salvador por Cuerno, 2000; en Nicaragua por Rocha, 2000b y Sosa Meléndez y Rocha, 2001; Avilés, 2003 y Zalaquet, 2003; en la ciudad hondureña de San Pedro Sula, por Boddiger, 2001. Para anteriores planteamientos en Nicaragua, que fueron desarrollados en el contexto de la Educación Popular, véase también Liebel, 1992 y CANTERA, 1992. Las investigaciones del IUDOP de 1996 (Cruz y Portillo Peña, 1998) y de 2000 (Santacruz Giralt y Concha-Eastman, 2001) desembocan en muchas recomendaciones para las políticas públicas. tección y seguridad ante un orden que los excluye" y a reconocer su comportamiento hacia dentro como una búsqueda de "espacios de pertenencia y adscripción identitaria a partir de los cuales es posible generar un sentido en común sobre el mundo" (Reguillo, 1998: 80). Estos comportamientos expresan el miedo, pero también la esperanza de que se pueda hacer "del mundo, del país, de la localidad, del futuro y del día, un mejor lugar para vivir" (op. cit: : 81).

Sin embargo, para poder percibir esto detrás de las formas de expresión, muchas veces violentas, de los jóvenes, es necesario abandonar la perspectiva criminalista y moralista, hasta ahora predominante, que sólo ve adolescentes "sin valores" o "desecho social" en los miembros de estas agrupaciones, y correr el riesgo de investigar el mundo de las pandillas urbanas desde una perspectiva cultural. En este sentido, el publicista colombiano Alonso Salazar (1990) se opuso ya a principios de la década de 1990 a explicar el comportamiento violento de los jóvenes —en su caso de los sicarios de Medellín- sólo como consecuencia de la injusticia social, del desempleo, de la violencia policial y del "dinero fácil” del narcotráfico. Sin negar estas realidades, había ubicado la violencia de los jóvenes en un contexto sociocultural de la región más amplio y que se remonta a tiempos pasados. De esta forma hizo visible la complejidad y la dimensión cultural de los rituales de violencia y muerte practicados por los jóvenes, y reconstruyó el tejido a partir del cual los adolescentes viven y sueñan. Salazar ayudó a entender "de qué dolorosas y a la vez gozosas experiencias; de qué sueños, frustraciones y rebeldías está hecho ese desecho social que conforman las bandas juveniles, esas que desde los barrios populares llevan la pesadilla hasta el centro de la ciudad y sus barrios bien habientes y bien pensantes" (Martín-Barbero, 1998: 25).

La pandillas existentes en las ciudades de América Latina son vistas, sin duda, como una amenaza por las personas que se cruzan con ellas o que, a menudo, sufren sus atropellos. Pero también significan una señal de que las sociedades deben cambiar, que no pueden seguir esquivando las injusticias sociales y los sufrimientos consiguientes. Las sociedades deberían abrirse a otros proyectos de vida, sobre todo de las generaciones más jóvenes. 


\section{Bibliografía}

Abaunza, Humberto y Ricardo Andino, 2002, La sociedad contra los jóvenes. Las pandillas de Esteli, Fundación Desafíos, Managua.

(eds.), 2003, Juventud y nuevos desafíos en Nicaragua, Fundación Desafíos, Managua.

Ardila Pedraza, Amparo, Javier Pombo Rodríguez y Rubén Darío Puerto, 1995, Pandillas Juveniles. Una historia de amor y desamor, Secretaría de Educación-Fundación FES, Santa Fé de Bogotá.

Arguedas, Carlos y Giannina Segnini, 2000, "Inquietud por brote de pandillas. Barras emergen en zonas marginales”, La Nación, 29 de octubre, San José, Costa Rica.

Argueta, Sandra et al., 1992, "Diagnóstico de los grupos llamados 'maras' en San Salvador. Factores psicosociales que prevalecen en los jóvenes que los integran”, Revista de Psicología de El Salvador, vol. 2, núm. 43, UCA, San Salvador, pp. 53-84.

AVANCSO, 1988, On Their Own. A Preliminar Study of Youth Gangs in Guatemala City, Asociación para el Avance de las Ciencias Sociales en Guatemala (Cuadernos de Investigación, núm. 4), Guatemala (edición en español: Por sí mismos: un estudio preliminar de las "maras" en la ciudad de Guatemala, 3a ed., 1996).

__, 1993, "Aquí corre la bola". Organización y relaciones sociales en una comunidad popular urbana, Asociación para el Avance de las Ciencias Sociales en Guatemala (Cuadernos de Investigación, núm. 9), Guatemala.

Avilés, Clara, 2003, "Resolución de conflictos entre pandillas", en Abaunza y Andino (eds.), Juventud y nuevos desafíos en Nicaragua, Fundación Desafíos, Managua, pp. 105-117.

Boddiger, David, 2001, "Pandilleros recanalizan energías", Noticias Aliadas, vol. 38, núm. 28, pp. 1-2.

CANTERA, 1992, ¿Cuál es la nota de los cipotes? Una experiencia de Educación Popular entre los niños y la comunidad, Centro de Educación y Comunicación Popular, Managua.

Castillo Berthier, Héctor, 1994, "Violencia urbana y cultura en la juventud contemporánea”, en Alberto Concha Eastman et al. (eds.), Ciudad y violencias en América Latina, Programa de Gestión Urbana, Quito, pp. 221-234.

Castro, Misael y Marlon Carranza, 2001, "La maras en Honduras", en Maras y pandillas en Centroamérica, UCA Publicaciones, Managua, pp. 219-332.

Cruz, José Miguel, 1997, "Los factores posibilitadores y las expresiones de la violencia en los noventa”, Estudios Centroamericanos, vol. 52, núm. 588, San Salvador, pp. 977992.

y Luis Armando Gónzalez, 1997, "Magnitud de la violencia en El Salvador”, Estudios Centromericanos, vol. 52, núm. 588, San Salvador, pp. 953-966.
— y Nelson Portillo Peña, 1998, Solidaridad y violencia en las pandillas del gran San Salvador. Más allá de la vida loca, UCA, San Salvador.

Cuerno, Lorena, 2000, "El lado oscuro de la calle. El caso extremo de las maras", JOVENes. Revista de Estudios sobre Juventud, nueva época, vol. 4, núm. 10, México, pp. 62-77.

De Cesare, Donna, 1998, “The Children of War. Street Gangs in El Salvador", NACLA Report on the Americas, vol. 32, núm. 1, pp. 21-29.

Dubet, François, 1987, La galère: jeunes en survie, Fayard, París.

Encinas Garza, José Lorenzo,1994, Bandas juveniles: perspectivas teóricas, Trillas, México.

Equipo de la Revista "Proceso" de la UCA de El Salvador, 2003, "Plan 'Mano Dura': violencia estatal contra las maras", envío-Revista Mensual de la Universidad Centroamericana, vol. 22, núm. 258, Managua, pp. 28-35.

Escobar, Francisco Andrés, 1996, "Por mi madre vivo y por mi barrio muero. Una aproximación al fenómeno de las maras", Estudios Centroamericanos, vol. 51, núm. 570, San Salvador, pp. 327-349.

Feixa, Carles, 2000, El reloj de arena. Culturas juveniles en México, Instituto Mexicano de la Juventud, México.

_ Fidel Molina y Carles Alsinet (eds.), 2002, Movimientos juveniles en América Latina. Pachucos, malandros, punketas, Ariel, Barcelona.

Fournier, Marco Vinicio, 2000, "Violencia y juventud en América Latina”, Nueva Sociedad, núm. 167, Caracas, pp. 147-156.

Gomezjara, Francisco A. et al., 1987a, Las bandas en tiempo de crisis, Nueva Sociología, México.

_ et al., 1987b, Pandillerismo en el estallido urbano, Fontamara, México.

IUDOP (Instituto Universitario de Opinión Pública), 1997, "Solidaridad y violencia. Los jóvenes pandilleros en el gran San Salvador", Estudios Centroamericanos, vol. 52, núm. 585/586, pp. 695-710.

Krauskopf, Dina, 1996, "Violencia juvenil: alerta social”, Revista Parlamentaria, vol. 4, núm. 3, San José, pp. 775-801.

Liebel, Manfred, 1992, Mala onda. La juventud popular en América Latina, Nicarao, Managua.

—_, 1994, Protagonismo infantil. Movimientos de niños trabajadores en América Latina, Nueva Nicaragua, Managua.

- 2000, La otra infancia. Niñez trabajadora y acción social, Ifejant, Lima.

—-, Bernd Overwien y Albert Recknagel (eds.), 2001, Working Children's Protagonism. Social Movements and Empowerment in Latin America, Africa and India, IKO, Francfort y Londres.

Maras y pandillas en Centroamérica, 2001, Equipo de Reflexión, Investigación y Comunicación (ERIC), Honduras; 
Instituto de Encuestas y Sondeo de Opinión (IDESO), Nicaragua; Instituto de Investigaciones Económicas y Sociales (IDIES), Guatemala; Instituto Universitario de Opinión Pública (IUDOP), El Salvador (eds.), UCA Publicaciones, Managua.

Martín-Barbero, Jesús, 1998, “Jóvenes: des-orden cultural y palimsestos de identidad", en "Viviendo a toda". Jóvenes, territorios culturales y nuevas sensibilidades, Siglo del Hombre Editores, Universidad Central, Bogotá, pp. 22-37.

Matus Lazo, Roger, 1997, El lenguaje del pandillero en Nicaragua, Centro de Investigación de la Realidad, Managua.

Merino, Juan, 2001, "Las maras en Guatemala", en Maras y pandillas en Centroamérica, UCA Publicaciones, Managua, pp. 109-218.

Moore, Joan M., 1991, Going Down to the Barrio. Homeboys and Homegirls in Change, Temple University Press, Filadelfia.

Muñoz Chacón, Sergio, 2000, Los Dorados, Editores Alambique, San José, Costa Rica.

Orellana Maglioni, Jesús Humberto, 1998, Violencia juvenil. La Pandilla, AECI-PNUD, Tegucigalpa.

Ramos, C. (ed.), 1998, América Central en los noventa: problemas de juventud, Imprenta Criterio, San Salvador.

Reguillo Cruz, Rossana, 1995, En la calle otra vez. Las bandas: identidad urbana y usos de la comunicación, $2^{\mathrm{a}}$ ed. ampliada, Iteso, Guadalajara.

__, 1998, "El año dos mil, ética, política y estéticas: imaginarios, adscripciones y prácticas juveniles. Caso mexicano", en "Viviendo a toda." Jóvenes, territorios culturales y nuevas sensibilidades, Siglo del Hombre Editores, Universidad Central, Bogotá, pp. 57-82.

— 2000 , "La invención del territorio. Procesos globales, identidades locales", en Umbrales. Cambios culturales, desafíos nacionales y juventud, Corporación Región, Medellín, pp. 117-139.

Rocha, José Luis, 2000a, "Pandillero: la mano que empuña el morsero", envío-Revista Mensual de la Universidad Centroamericana, vol. 19, núm. 216, Managua, pp. 17-25.

_ Mensual de la Universidad Centroamericana, vol. 19, núm. 219, Managua, pp. 13-22.

__ 2001, "Balance de los estudios en los cuatro países", en Maras y pandillas en Centroamérica, UCA Publicaciones, Managua, pp. 431-444.

__ 2003, "Los tatuajes de los pandilleros: estigma, identidad y arte", envío-Revista Mensual de la Universidad Centroamericana, vol. 22, núm. 258, pp. 42-50.

Rodgers, Dennis, 1997, "Un antropólogo-pandillero en un barrio de Managua”, envío-Revista Mensual de la Universidad Centroamericana, vol. 16, núm. 184, pp. 10-16.

Salazar J., Alonso, 1990, No nacimos pa' semilla. La cultura de las bandas juveniles en Medellín, CINEP, Medellín.
__ 2002, "Sicarios. Una mirada a las violencias colombianas", en Feixa, Molina y Alsinet (eds.), Movimientos juveniles en América Latina. Pachucos, malandros, punketas, Ariel, Barcelona, pp. 103-112.

Salomón, Leticia, 1993, La violencia en Honduras 1980-1993, $\mathrm{CEDOH}, \mathrm{CONADEH}$, Tegucigalpa.

__ Julieta Castellanos y Mirna Flores, 1999, La delincuencia juvenil. Los menores infractores en Honduras, $\mathrm{CEDOH}$, Tegucigalpa.

Santacruz Giralt, María L. y Alberto Concha-Eastman, 2001, Barrio adentro. La solidaridad violenta de las pandillas, IUDOP, San Salvador.

—_ y José Miguel Cruz Alas, 2001, "La mara en El Salvador", en Maras y pandillas en Centroamérica, UCA Publicaciones, Managua, pp. 15-107.

Savenije, M. y H. Lodewijkx, 1998, "Aspectos expresivos e instrumentales de la violencia entre pandillas juveniles salvadoreñas: una investigación de campo", en Ramos (ed.), América Central en los noventa: problemas de juventud, Imprenta Criterio, San Salvador.

Serna Hernández, Leslie, 2000, "Las organizaciones juveniles. De los movimientos sociales a la autogestión”, JOVENes. Revista de Estudios sobre Juventud, nueva época, vol. 4, núm. 11, pp. 114-130.

Smutt, Marcela y Jenny Lissette Miranda, 1998, El fenómeno de las pandillas en El Salvador, UNICEF-FLACSO (serie Adolescencia, núm. 2), San Salvador.

Sosa Meléndez, Juan-José y José Luis Rocha, 2001, "Las pandillas en Nicaragua", en Maras y pandillas en Centroamérica, UCA Publicaciones, Managua, pp. 333-430.

Urteaga Castro-Pozo, Maritza, 2000, "Formas de agregación juvenil”, en José Antonio Pérez Islas (coord.), Jóvenes: Una evaluación de conocimiento. La investigación sobre juventud en México 1986-1999, vol. 2, Instituto Mexicano de la Juventud, México, pp. 405-516.

Valenzuela Arce, José Manuel, 1988, A la brava ése: Identidades juveniles en México: cholos, punks y chavos banda, El Colegio de la Frontera Norte, Tijuana.

_, 2002 , "De los pachucos a los cholos. Movimientos juveniles en la frontera México-Estados Unidos", en Feixa, Molina y Alsinet (eds.), Movimientos juveniles en América Latina. Pachucos, malandros, punketas, Ariel, Barcelona, pp. 11-34.

Vigil, James Diego, 1994, Barrio Gangs. Street Life and Identity in Southern California, $4^{\text {a }}$ ed., University of Texas Press, Austin.

— 2002, A Rainbow of Gangs, University of Texas Press, Austin.

Zalaquet, Mónica, 2003, "Las pandillas juveniles en Nicaragua”, en Abaunza y Andino (eds.), Juventud y nuevos desafios en Nicaragua, Fundación Desafíos, Managua, pp. 119-131. 